\title{
Stepped osteotomy of femoral head autograft for acetabular reconstruction in total hip arthroplasty for dysplasia of the hip: 3 to 12 years' results
}

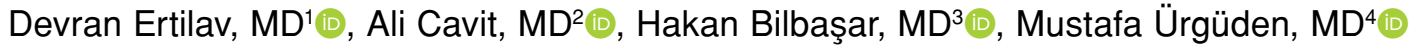 \\ ${ }^{1}$ Department of Orthopedics and Traumatology, Aydın State Hospital, Aydın, Turkey \\ 2Department of Orthopedics and Traumatology, Uludağ University Faculty of Medicine, Bursa, Turkey \\ ${ }^{3}$ Department of Orthopedics and Traumatology, Private Akdeniz Hospital, Antalya, Turkey \\ ${ }^{4}$ Department of Orthopedics and Traumatology, Akdeniz University Faculty of Medicine, Antalya, Turkey
}

Surgeons may encounter many technical difficulties when performing total hip arthroplasty in patients with developmental dysplasia of the hip (DDH). Locating the acetabular cup correctly and providing adequate coverage can be particularly difficult in these hips. Osteointegration becomes an important problem in hips in which the acetabular roof is applied to provide coverage. ${ }^{[1]}$ Harris et al. ${ }^{[2]}$ first described the bulk autogenous graft technique in 1977 to obtain superolateral bone coverage. While earlymidterm results were promising, long-term outcomes were unclear. In Harris' series, $21 \%$ of patients had radiographic evidence of loosening within seven years, and the results of an average of 16 years showed a high incidence of acetabular failures due to component loosening and graft collapse. ${ }^{[3,4]}$ Recently, bulk autografts with both cemented and uncemented implants have been used, and long-term positive results have been reported. ${ }^{[5-8]}$

Integration and stability of autografts are defined as the keys to success in this technique. ${ }^{[9]}$ Due to

\footnotetext{
Received: February 27, 2020

Accepted: April 06, 2020

Published online: June 18, 2020
}

Correspondence: Ali Cavit, MD. Uludağ Üniversitesi Tıp Fakültesi Ortopedi ve Travmatoloji Anabilim Dalı, 16059 Nilufer, Bursa, Türkiye.

E-mail: alicavit@hotmail.com

Doi: $10.5606 /$ ehc. 2020.74300

Citation: Ertilav D, Cavit A, Bilbaşar H, Ürgüden M. Stepped osteotomy of femoral head autograft for acetabular reconstruction in total hip arthroplasty for dysplasia of the hip: 3 to 12 years' results. Jt Dis Relat Surg 2020;31(2):353-359.

\section{ABSTRACT}

Objectives: This study aims to describe a stepped osteotomy technique applied to the femoral head autograft to keep the graft volume at a sufficient level, provide primary stability, and direct cancellous-cancellous bone contact.

Patients and methods: In this retrospective study, 24 hips of 20 patients ( 5 males, 15 females; mean age 53 years; range, 43 to 68 years) with dysplasia of the hip (DDH) who underwent total hip arthroplasty with femoral head stepped osteotomy technique were evaluated between April 2003 and June 2010. Patients' age, gender, operation side, and postoperative complications were recorded. Aseptic loosening of the acetabular cup and graft integration/resorption were evaluated radiographically. Radiological evaluations were performed according to the methods of DeLee and Charnley, and Mulroy and Harris. Functional status of the patients was determined according to the criteria of Merle d'Aubigné and Postel, and Harris hip score (HHS).

Results: The mean follow-up period was 5.5 years (range, 3 to 12 years). None of the patients had any complications in the early postoperative period. In all patients, the percentage of acetabular component coverage by the graft was measured as $27 \%$ (range, 19 to $38 \%$ ) on average. At the last follow-up, all patients were satisfied with the result and there was no sign of clinically loosening, osteointegration was complete, and there was no radiographic evidence of graft resorption or collapse of any hip. The overall Merle d'Aubigné scores and HHSs of the patients significantly improved at the final follow-up.

Conclusion: This stepped osteotomy technique increases the probability of osteointegration, reduces the need for early revision, and provides reliable stability with satisfactory clinical and radiological midterm results.

Keywords: Acetabularia, arthroplasty, autograft, osteotomy.

the slow and inadequate osteointegration of bulk autografts, it has been shown to be less resistant to stresses under repetitive loadings. ${ }^{[10]}$ The main factors 
affecting graft incorporation are graft stability and bone-graft contact. ${ }^{[2-9]}$ In this study, we aimed to describe a stepped osteotomy technique applied to the femoral head autograft to keep the graft volume at a sufficient level, provide primary stability, and direct cancellous-cancellous bone contact.

\section{PATIENTS AND METHODS}

In this retrospective study, 24 hips in 20 patients (5 males, 15 females; mean age 53 years; range, 43 to 68 years) with DDH who underwent total hip arthroplasty with femoral head stepped osteotomy technique were evaluated at Akdeniz University Faculty of Medicine between April 2003 and June 2010. Patients were classified radiologically according to the Crowe and Hartofilakidis classification system preoperatively. According to the Crowe classification, there were there, 18, and three type I, type II, and type III hips, respectively. According to the Hartofilakidis classification, there were eight and 16 type $\mathrm{A}$ and type $\mathrm{B}$ hips, respectively. The study protocol was approved by the Akdeniz University Faculty of Medicine Ethics Committee. A written informed consent was obtained from each patient. The study was conducted in accordance with the principles of the Declaration of Helsinki.

Immediate postoperative radiographs were compared with recent radiographs of patients. Patients were followed-up with radiographs every six months. Radiological evaluation was performed by a senior surgeon and two blinded orthopedic surgeons. The inclination angle of the acetabular cup was assessed in relation to the Kohler line postoperatively. The coverage area of the acetabular cup was expressed as the percentage of the horizontal distance between the most medial point of the cup, and the most lateral edge (Figure 1). Graft integration was assessed by observing the disappearance of the graft-bone interface and the appearance of bridge trabeculae. ${ }^{[11]}$

The horizontal and vertical placement of the acetabular cup was measured as described by Russotti and Harris ${ }^{[12]}$ graft resorption was assessed at each follow-up, and the acetabular cup-bone interface was evaluated according to the regions described by DeLee and Charnley. ${ }^{[13]}$ Loosening of the acetabular cup was evaluated according to the criteria determined by Mulroy and Harris, ${ }^{[14]}$ including displacement of more than $2 \mathrm{~mm}$ in the horizontal and/or vertical plane, a change of more than four degrees of inclination, or a radiolucent line of more than $1 \mathrm{~mm}$.
The range of motion and walking ability of the patients were evaluated at the final follow-up. Pain and functional status of the patients were determined according to the criteria of Merle d'Aubigné and Postel, and Harris hip score (HHS). ${ }^{[15,16]}$

Regarding the surgical technique, a posterolateral incision was used in all patients in the lateral decubitus position. The transverse acetabular ligament or ligamentum teres (if present) were followed to find the true acetabulum. Retractors were placed around the true acetabulum so that it could be seen clearly. The reaming process was begun with the smallest acetabular reamers which fit to the size of the acetabulum of each patient, and the reamers were enlarged until there was subchondral bone bleeding. Since there is usually superolateral acetabular roof failure after this reaming process, the smallest volume of the graft was taken from the patients' own femoral head and was prepared to cover the defect. A stepped osteotomy was performed on the graft. This stepped osteotomy was measured relative to the defective area on the acetabulum, and both the depth and size were adjusted to ensure proper contouring. We tried to describe this technique by creating an acetabular superolateral insufficiency on a pelvis model (Figure 2).

Graft location was determined on the acetabular roof. All soft tissue, including osteophytes and capsule residues in this area, was removed, and bone was decorticated. After reaching the spongious bone, many holes were created by drilling through the spongious

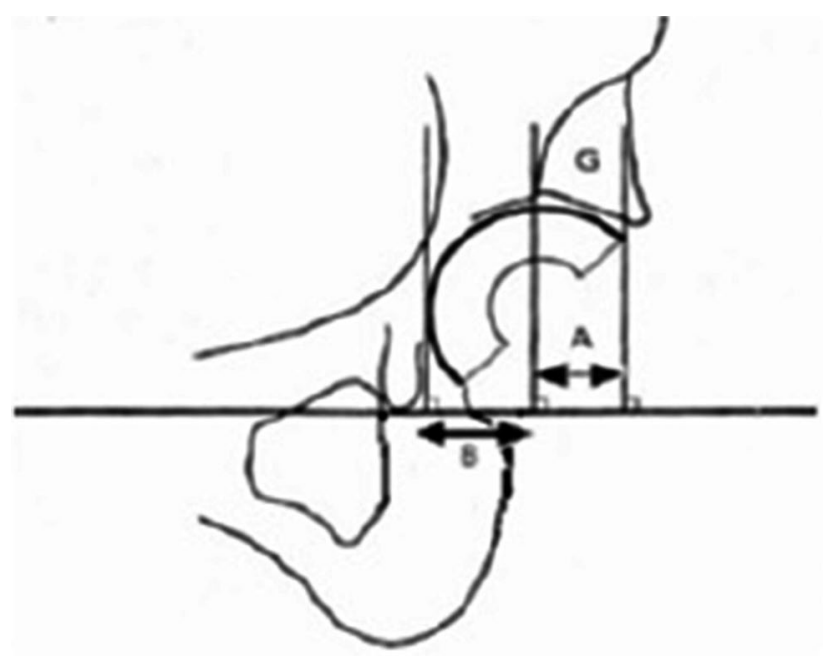

FIGURE 1. Evaluation of acetabular roof graft. $[A /(A+B)] \times 100$ : Percentage of acetabular component coverage by graft; $[B /(A+B)] \times 100$ : Percentage of coverage of acetabular component. 
bone to supply enough bleeding. Subsequently, the graft was placed in the region prepared in the acetabulum roof. The stepped graft was compressed very tightly with one to three compressive screws. Then, the reaming process continued. It was checked that the stepped graft was more compressed during each reaming step. After adequate enlargement was achieved, acetabular cup trials were attempted by giving appropriate anteversion and abduction angle. After ensuring that the acetabular cup was adequately covered and tightened, the acetabular cup was placed and fixed with one to two screws directed to the ilium. At the last stage, the insert was placed in the acetabular cup (Figure 3). Cementless hydroxyapatite coated hip systems were used in all patients.

\section{Statistical analysis}

Descriptive statistics are presented as the frequency, percent, mean \pm standard deviation, median,
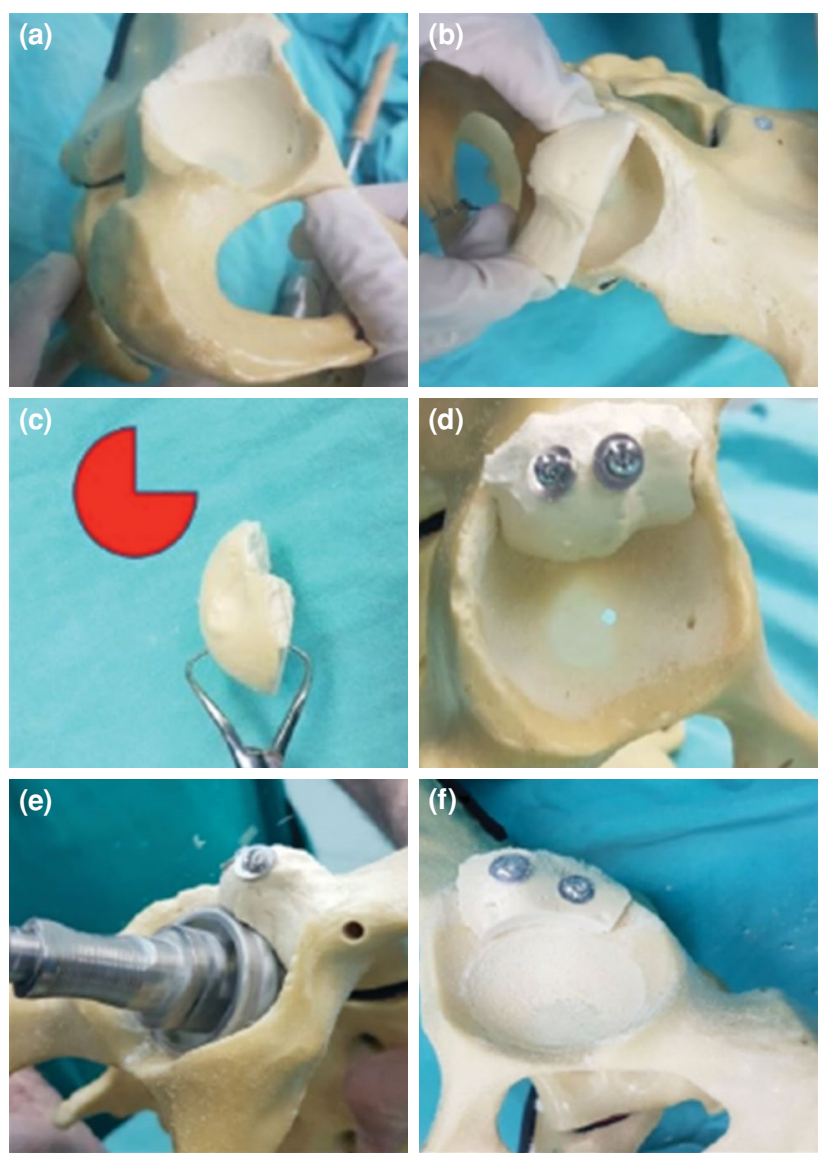

FIGURE 2. (a) Acetabular superolateral insufficiency model. (b) Taking measurements of autograft before stepped osteotomy. (c) Stepped osteotomy. (d) Compression of graft with two screws. (e) Reaming again with large acetabular reamers (graft is more compressed at this stage). (f) Acetabular cup is ready to be placed with adequate coverage. minimum and maximum values. The compatibility of continuous variables for normal distribution was investigated using analytical methods (KolmogorovSmirnov/Shapiro-Wilk test). All statistical analyses were performed with IBM SPSS version 22.0 software (IBM Corp., Armonk, NY, USA).

\section{RESULTS}

The mean follow-up period was 5.5 years (range, 3 to 12 years). The left hip was operated in nine patients, right hip in seven patients, and bilateral hips in four patients (all females).

None of the patients had any complications such as wound hematomas, infections, or neuropraxias
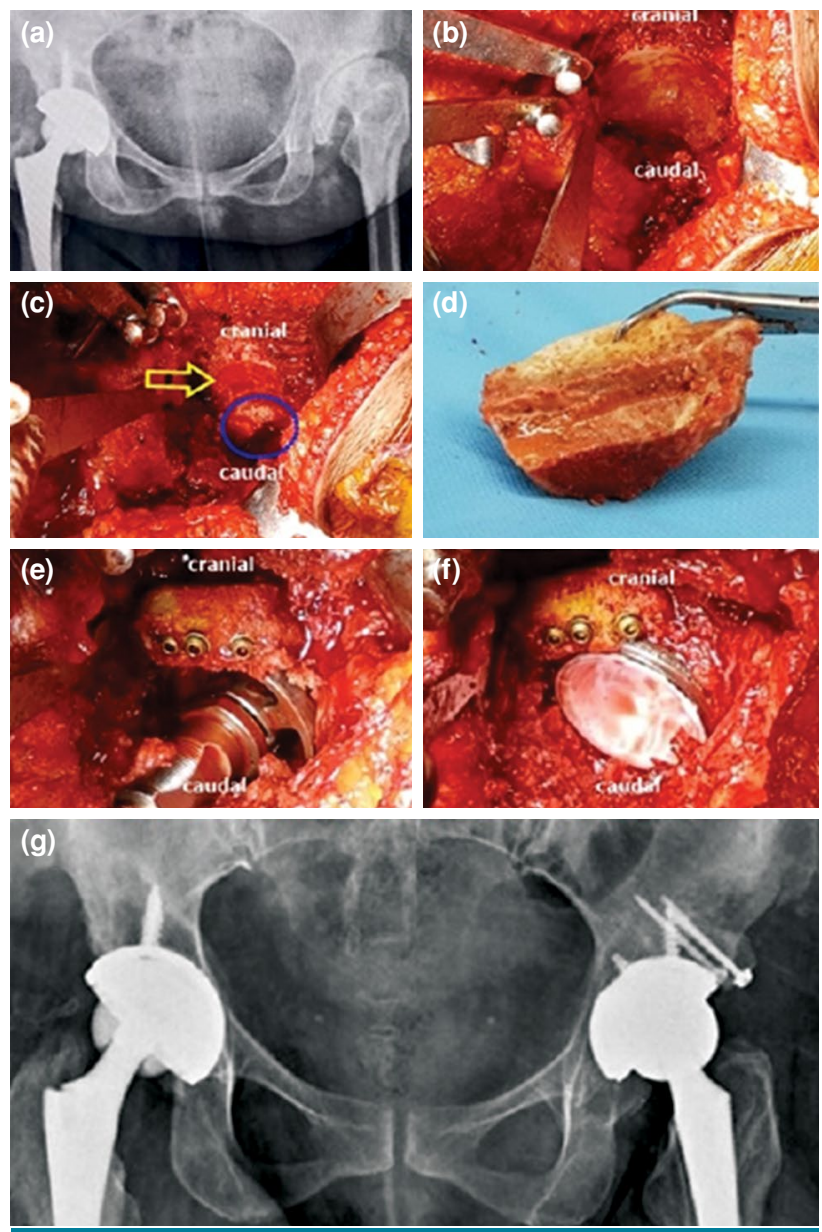

FIGURE 3. (a) Preoperative X-ray. (b) Condition of acetabulum after reaming with small reamers. (c) Blue circle shows acetabulum. Area where graft is to be placed (shown by yellow arrow) is ready, spongious bone is fully reached, and sufficient bleeding is provided with drilling. (d) Femoral head autograft prepared by stepped osteotomy is ready to be placed. (e) Compression of graft with screws and reaming process. (f) Acetabular cup and insert are placed. (g) Postoperative X-ray of patient. 


\begin{tabular}{|c|c|c|c|c|}
\hline \multicolumn{5}{|c|}{$\begin{array}{l}\text { TABLE I } \\
\text { aristics of patients, follow-up periods and graft coverage ratios }\end{array}$} \\
\hline Patients & Age/Gender & Crowe type & Graft coverage (\%) & Duration of follow-up (years) \\
\hline 1 & $49 / F$ & 2 & 25 & 3 \\
\hline 2 & $43 / F$ & 2 & 20 & 3 \\
\hline 3 & $56 / \mathrm{F}$ & 1 & 24 & 5 \\
\hline 4 & $57 / F$ & 2 & 25 & 4 \\
\hline 5 & $58 / F$ & 3 & 27 & 3 \\
\hline 6 & $52 / F$ & 2 & 28 & 4 \\
\hline 7 & $45 / F$ & 1 & 31 & 11 \\
\hline 8 & $68 / F$ & 2 & 29 & 8 \\
\hline 9 & $68 / F$ & 2 & 30 & 8 \\
\hline 10 & $52 / F$ & 2 & 28 & 4 \\
\hline 11 & $56 / M$ & 2 & 25 & 4 \\
\hline 12 & $54 / F$ & 3 & 29 & 11 \\
\hline 13 & $53 / F$ & 2 & 25 & 12 \\
\hline 14 & $51 / F$ & 2 & 22 & 3 \\
\hline 15 & $63 / M$ & 2 & 36 & 5 \\
\hline 16 & $53 / \mathrm{F}$ & 1 & 30 & 4 \\
\hline 17 & $47 / F$ & 2 & 38 & 8 \\
\hline 18 & $47 / F$ & 2 & 30 & 8 \\
\hline 19 & $50 / F$ & 2 & 19 & 4 \\
\hline 20 & $52 / \mathrm{M}$ & 2 & 26 & 3 \\
\hline 21 & $47 / M$ & 2 & 29 & 4 \\
\hline 22 & $55 / F$ & 3 & 21 & 4 \\
\hline 23 & $45 / \mathrm{M}$ & 2 & 27 & 5 \\
\hline 24 & $57 / F$ & 2 & 33 & 4 \\
\hline Average & 53 & & 27 & 5.5 \\
\hline
\end{tabular}

in the early postoperative period. In all patients, the percentage of acetabular component coverage by the graft was measured as $27 \%$ (range, 19 to $38 \%$ ) on average (Table I). The percentage of coverage of the acetabular component ranged from 80 to $96 \%$, with an average of $94 \%$.

Functional status of the 20 patients (24 hips) was evaluated at the final follow-up. The mean overall Merle d'Aubigné hip score improved from 2.89 (range, 1 to 6) preoperatively to 9.26 (range, 4 to 12) at final follow-up. Nineteen out of 24 hips had good and very good results. The mean walking ability score increased from a mean of 1.52 (range, 1 to 4 ) preoperatively to a mean of 4.52 (range, 3 to 6) postoperatively; the amount of pain decreased to 1.36 (range, 0 to 4 ) from 4.84 (range, 1 to 6) at the final follow-up. When examining the range of motion, the mean flexion range was $43^{\circ}$ (range, $0^{\circ}$ to $100^{\circ}$ ) preoperatively and $94^{\circ}$ (range, $40^{\circ}$ to $115^{\circ}$ ) at the final follow-up. Abduction increased from $14^{\circ}$ (range, $5^{\circ}$ to $36^{\circ}$ ) to $27^{\circ}$ (range, $5^{\circ}$ to $40^{\circ}$ ).

According to the HHS system, functional status of the patients was "poor" with a mean of 37 points (range, 22 to 46 points) preoperatively. At the final follow-up, it was "excellent" with a mean of 90 points (range, 65 to 95 points).

On follow-up radiographs, osteointegration was complete after a mean of one year (Figure 4). Cortical continuity between graft and ilium was achieved in all patients (Figure 5). There was no radiographic evidence of graft resorption or collapse. A 45-year-old female patient who was operated because of a Crowe type I dysplastic hip had radiological findings of osteolysis. The fixation of the graft was achieved with one screw. The coverage of the acetabular component was $96 \%$, and the acetabular component coverage 
by the graft was $31 \%$ in that patient. Although the patient did not have any clinical complaints, postoperative $11^{\text {th }}$-year radiography showed that the screw applied for acetabular graft fixation backed out,
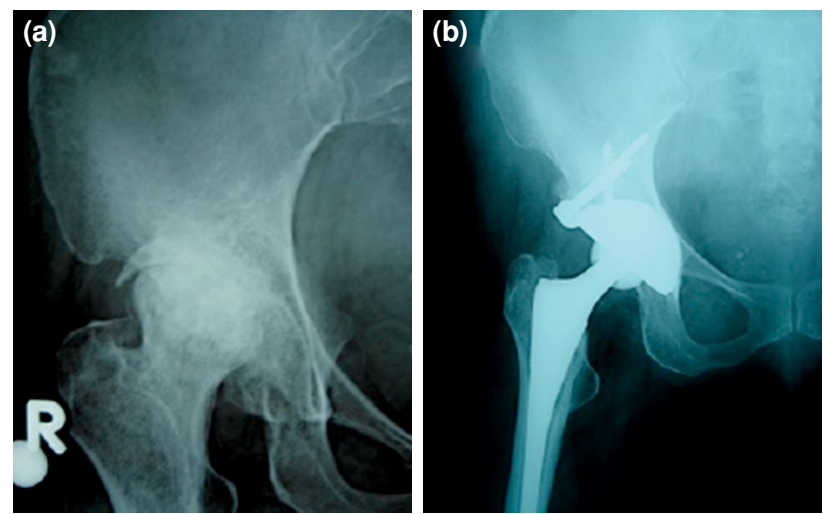

FIGURE 4. (a) Preoperative X-ray. (b) Postoperative $12^{\text {th }}$ year $\mathrm{X}$-ray.
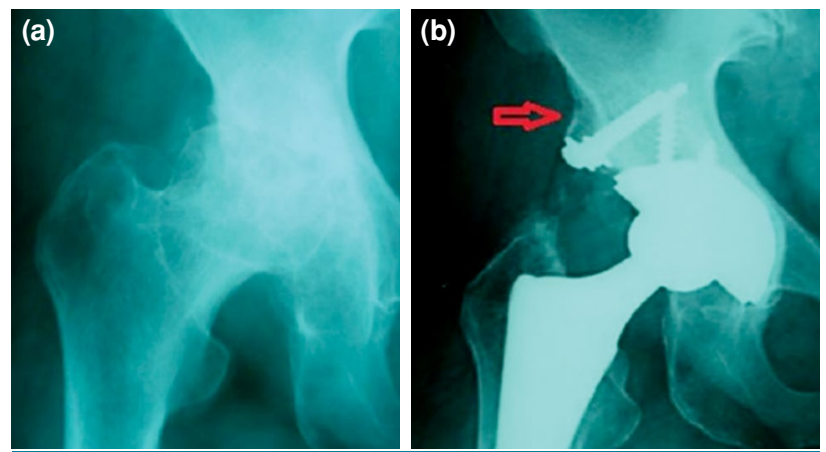

FIGURE 5. (a) Preoperative X-ray. (b) Postoperative eighth year X-ray (red arrow shows cortical continuity between graft and ilium). and there were radiolucent areas around the screw. In addition, the presence of radiolucent space around the acetabular cup suggested that the reason for screw backing out was osteolysis rather than a graft incorporation problem (Figure 6). None of the other 23 hips had such a problem, and none of the patients needed revision. At the last follow-up, all patients were satisfied with the result.

\section{DISCUSSION}

Total hip arthroplasty is challenging in DDH, as dysplastic hips have a shallow articular cavity, increased anteversion, thin anterior wall, low bone stock and insufficient coverage of the femoral head. ${ }^{[1]}$ Different methods have been described to solve the problem of covering the superolateral region of the acetabulum. Some of these methods include proximally placed small acetabular cups, placement of the cup by penetration of the medial wall (medial protrusion technique), iliac bone sliding grafting, and lateral bulk grafting using an autograft or an allograft. . $[-7,12,17-20]^{-}$

In our technique; first, we found the true acetabulum, which is very important regarding biomechanics, and then we decorticated the defect in the superolateral acetabulum until the cancellous bone was reached. We cut the femoral head in two, determined the location of the graft, and held it in the smallest volume with enough graft size; thus eliminating large volume graft problems. We cut the femoral head in a "stepped form" and placed it in a way that cancellous-cancellous bone contact was maximized, and we firmly fixed it with one to three compressive screws. At each stage of reaming, the graft was pressed even more so its stability increased.
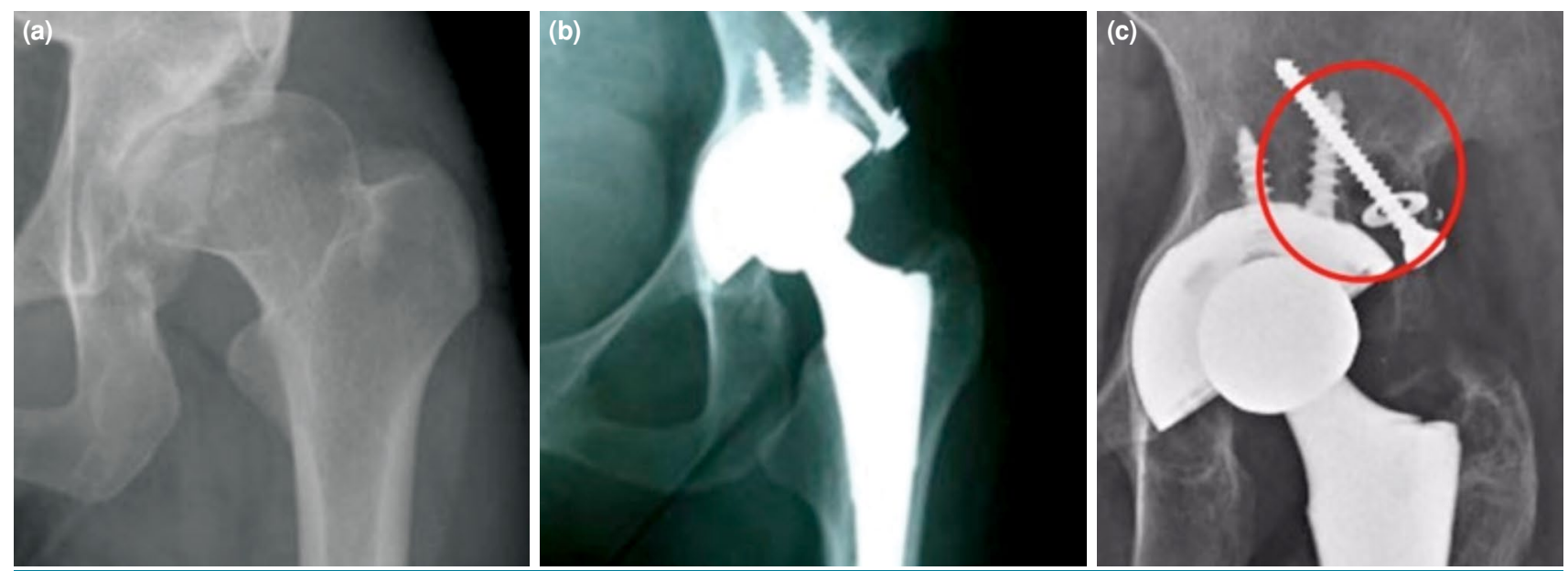

FIGURE 6. (a) Preoperative X-ray. (b) Postoperative X-ray. (c) Postoperative $11^{\text {th }}$ year X-ray, screw backed out and findings of osteolysis. 
We were careful that the graft did not exceed $40 \%$ of the acetabular cover. All these applications increase graft revascularization and optimize the biological process for graft integration, which leads to increased bone stock and decrease in both long-term resorption and failure rates. ${ }^{[21]}$

The lateral bulk grafting technique has been preferred by many authors because it can be used readily from the head of the femur, permits placement of larger components, and is structurally supportive. Another advantage is the increased pelvic bone stock. ${ }^{[22]}$ This benefit is an important issue when the age of onset of secondary degenerative changes in this population group is taken into consideration.

Published results of bulk autografts used in DDH vary probably because of differences in patient selection, the severity of dysplasia, bone quality, and technique of application of both bone graft and components. ${ }^{[22]}$ Sufficient coverage of the acetabular component should be provided for stability in DDH. The graft size used for this purpose influences clinical success. ${ }^{[4,23]}$ Despite good early results in Mulroy and Harris case series, ${ }^{[14]}$ graft failure and failure because of resorption have been reported in up to $20 \%, 46 \%$, and $60 \%$ at the end of the $7^{\text {th }}, 11^{\text {th }}$, and $16^{\text {th }}$ years, respectively. At the same time, the failure rate was $67 \%$ for grafts covering $40 \%$ or more (40 to $70 \%$ ) of the cemented acetabular component, whereas the failure rate was $21 \%$ for grafts covering $40 \%$ or less (20 to $40 \%)$. According to Iona et al., ${ }^{[24]}$ grafts covering more than $40 \%$ of the acetabular component are responsible for poor outcomes in long-term follow up.

Similarly, Zahar et al. ${ }^{[25]}$ also found that the rate of failure in large-volume graft cases was $84 \%$ at 11.6 years and stated that this failure would increase as the duration of follow-up increases. Some surgeons who have seen poor long-term outcomes of large-volume grafting have begun to apply vascular pedicled iliac wing grafts and have reported successful results. ${ }^{[26,27]}$ Pizarro et al. ${ }^{[11]}$ added iliac osteotomy during acetabular reconstruction and indicated that it provided both early stabilization and reliable graft consolidation. However, while the midterm results of this method are satisfactory, long-term results are not known. Kobayashi et al. ${ }^{[7]}$ suggested that opening many holes to the ilium with a perforator could increase blood flow and cancellous-cancellous bone contact, thereby increasing graft fusion.

The consolidation of the graft used for acetabular coverage is achieved by new bone formation after partial resorption. This process is referred to as "creeping substitution" and depends on the blood supply of the graft. Marti et al. ${ }^{[23]}$ emphasized that the fixation of two to three small autografts instead of large grafts provided earlier vascularization, and reduced the possibility of resorption to avoid loosening because of resorption in large structural grafts.

Previous publications have reported that graft stability and graft-bone contact are two of the most critical factors for graft incorporation. ${ }^{[2,9,10,20]}$ In the original description by Harris, ${ }^{[2]}$ the femoral head is curved to fit the ilium, and a notch is made in the ilium where the femoral head is placed. Subsequently, other authors have proposed cutting the femoral head to provide cancellous bone contact. ${ }^{[8,28]}$

Some factors limit our study. We used standard anteroposterior - lateral radiographs of the hip and evaluated the hip with two-dimensional radiographs. In the follow-up period, we did not evaluate the graft and acetabular cup as three-dimensional. Also, because of the lack of data obtained by magnetic resonance imaging, bone scintigraphy, and bone biopsy, we cannot assess the rate or extent of invasion of the bone graft by the repair tissue, or the metabolic status of autologous bone around and in the autograft. However, after the graft was applied, the progression of the trabeculae to the graft, presence of a radiodense line as a continuation of the lateral wall of the iliac bone, and absence of any change in this line during follow-up suggest that the autograft was successfully incorporated.

In conclusion, we believe that this stepped osteotomy technique both increases the probability of osteointegration and reduces the need for early revision. Even the midterm results of this described technique are very satisfactory, while longer follow-up is required to confirm the clinical success of this procedure.

\section{Declaration of conflicting interests}

The authors declared no conflicts of interest with respect to the authorship and/or publication of this article.

\section{Funding}

The authors received no financial support for the research and/or authorship of this article.

\section{REFERENCES}

1. Sakellariou VI, Christodoulou M, Sasalos G, Babis GC. Reconstruction of the Acetabulum in Developmental Dysplasia of the Hip in total hip replacement. Arch Bone Jt Surg 2014;2:130-6.

2. Harris WH, Crothers $\mathrm{O}$, Oh I. Total hip replacement and femoral-head bone-grafting for severe acetabular deficiency 
in adults. J Bone Joint Surg [Am] 1977;59:752-9.

3. Gerber SD, Harris WH. Femoral head autografting to augment acetabular deficiency in patients requiring total hip replacement. A minimum five-year and an average seven-year follow-up study. J Bone Joint Surg [Am] 1986;68:1241-8.

4. Shinar AA, Harris WH. Bulk structural autogenous grafts and allografts for reconstruction of the acetabulum in total hip arthroplasty. Sixteen-year-average follow-up J Bone Joint Surg [Am] 1997;79:159-68.

5. Iida $H$, Matsusue $Y$, Kawanabe K, Okumura H, Yamamuro T, Nakamura T. Cemented Total Hip Arthroplasty With Acetabular Bone Graft for Developmental Dysplasia. Longterm Results and Survivorship Analysis. J Bone Joint Surg [Br] 2000;82:176-84.

6. Inao $S$, Matsuno $T$. Cemented total hip arthroplasty with autogenous acetabular bone grafting for hips with developmental dysplasia in adults: the results at a minimum of ten years. J Bone Joint Surg [Br] 2000;82:375-7.

7. Kobayashi S, Saito N, Nawata M, Horiuchi H, Iorio R, Takaoka K. Total hip arthroplasty with bulk femoral head autograft for acetabular reconstruction in developmental dysplasia of the hip. J Bone Joint Surg [Am] 2003;85:615-21.

8. Hendrich C, Mehling I, Sauer U, Kirschner S, Martell JM. Cementless acetabular reconstruction and structural bone-grafting in dysplastic hips. J Bone Joint Surg [Am] 2006;88:387-94.

9. Young SK, Dorr LD, Kaufman RL, Gruen TA. Factors related to failure of structural bone grafts in acetabular reconstruction of total hip arthroplasty. J Arthroplasty 1991;6:S73-82.

10. Stevenson S, Emery SE, Goldberg VM. Factors affecting bone graft incorporation. Clin Orthop Relat Res 1996;324:66-74.

11. Pizarro FC, Young SW, Blacutt JH, Mojica R, Cruz JC. Total hip arthroplasty with bulk femoral head autograft for acetabular reconstruction in developmental dysplasia of the hip. ISRN Orthop 2013;2013:794218.

12. Russotti GM, Harris WH. Proximal placement of the acetabular component in total hip arthroplasty. A longterm follow-up study. J Bone Joint Surg [Am] 1991;73:587-92.

13. DeLee JG, Charnley J. Radiological demarcation of cemented sockets in total hip replacement. Clin Orthop Relat Res 1976;121:20-32.

14. Mulroy RD Jr, Harris WH. Failure of acetabular autogenous grafts in total hip arthroplasty. Increasing incidence: a follow-up note. J Bone Joint Surg [Am] 1990;72:1536-40.

15. Ugino FK, Righetti CM, Alves DP, Guimarães RP, Honda EK, Ono NK. Evaluation of the reliability of the modified Merle d'Aubigné and Postel Method. Acta Ortop Bras 2012;20:213-7.
16. Harris WH. Traumatic arthritis of the hip after dislocation and acetabular fractures: treatment by mold arthroplasty. An end-result study using a new method of result evaluation. J Bone Joint Surg [Am] 1969;51:737-55.

17. Pagnano W, Hanssen AD, Lewallen DG, Shaughnessy WJ. The effect of superior placement of the acetabular component on the rate of loosening after total hip arthroplasty. J Bone Joint Surg [Am] 1996;78:1004-14.

18. Dorr LD, Tawakkol S, Moorthy M, Long W, Wan Z. Medial protrusio technique for placement of a porous-coated, hemispherical acetabular component without cement in a total hip arthroplasty in patients who have acetabular dysplasia. J Bone Joint Surg [Am] 1999;81:83-92.

19. Hartofilakidis G, Stamos K, Karachalios T, Ioannidis TT, Zacharakis N. Congenital hip disease in adults. Classification of acetabular deficiencies and operative treatment with acetabuloplasty combined with total hip arthroplasty. J Bone Joint Surg [Am] 1996;78:683-92.

20. Ikeuchi M, Kawakami T, Kitaoka K, Okanoue Y, Tani T. Total hip arthroplasty with a sliding iliac graft for acetabular dysplasia. J Bone Joint Surg [Br] 2005;87:635-9.

21. Atik OŞ. Is there something new and interesting in my article? Eklem Hastalik Cerrahisi 2019;30:69.

22. Farrell CM, Berry DJ, Cabanela ME. Autogenous femoral head bone grafts for acetabular deficiency in total-hip arthroplasty for developmental dysplasia of the hip: long-term effect on pelvic bone stock. J Arthroplasty 2005;20:698-702.

23. Marti RK, Schüller HM, van Steijn MJ. Superolateral bone grafting for acetabular deficiency in primary total hip replacement and revision. J Bone Joint Surg [Br] 1994;76:728-34.

24. Inao S, Gotoh E, Ando M. Total hip replacement using femoral neck bone to graft the dysplastic acetabulum. Follow-up study of 18 patients with old congenital dislocation of the hip. J Bone Joint Surg [Br] 1994;76:735-9.

25. Zahar A, Papik K, Lakatos J, Cross MB. Total hip arthroplasty with acetabular reconstruction using a bulk autograft for patients with developmental dysplasia of the hip results in high loosening rates at mid-term follow-up. Int Orthop 2014;38:947-51.

26. Delimar D, Bohacek I, Pecina M, Bicanic G. Acetabular roof reconstruction with pedicled iliac graft: ten years later. Int Orthop 2014;38:199-201.

27. Delimar D, Cicak N, Klobucar H, Pećina M, Korzinek K. Acetabular roof reconstruction with pedicled iliac graft. Int Orthop 2002;26:344-8.

28. Shetty AA, Sharma P, Singh S, Tindall A, Kumar SV, Rand C. Bulk femoral-head autografting in uncemented total hip arthroplasty for acetabular dysplasia: results at 8 to 11 years follow-up. J Arthroplasty 2004;19:706-13. 